\title{
LabVIEW based e-learning portal for virtual mass transfer operations laboratory
}

\author{
Amrita Agarwal · Ramgopal Uppaluri • \\ Anil Verma
}

Received: 28 May 2012/Accepted: 23 October 2012/Published online: 6 November 2012

(C) CSI Publications 2012

\begin{abstract}
This article, introduces the unique concept of virtual mass transfer laboratory, an exercise that has been developed by IIT Guwahati under the auspices of Ministry of Human Resource and Development (MHRD) under National Mission on Education through ICT. The virtual mass transfer laboratory constitutes eight distinct virtual laboratory modules that cover various aspects of mass transfer operations, a key subject in chemical engineering education and practice. While all modules are simulation based, in addition to the most essential virtual lab simulator, the virtual laboratory modules essentially include all aspects of virtual laboratory education namely theory, experimental procedure, animation, quizzes etc. The virtual laboratory environment enabled an improved learning of chemical engineering, as learning is often better achieved by practice and repeated experimentation/observation in real world scenarios. Further, field trails and user friendly workshops have also been organized to obtain real time feedback and these have been extremely beneficial to improve the quality of the technical content as well as e-learning in the virtual mass transfer laboratories. Thereby a framework to explore possibilities to further creative component in chemical engineering has been developed.
\end{abstract}

Keywords Virtual lab - LabVIEW - Virtual instrument . Mass transfer $\cdot$ Simulation

A. Agarwal · R. Uppaluri $(\bowtie) \cdot$ A. Verma

Department of Chemical Engineering, Indian Institute of

Technology Guwahati, Guwahati 781039, Assam, India

e-mail: ramgopalu@iitg.ernet.in

\section{Introduction}

Mass transfer operations constitute an important subject in chemical engineering education and practice. Ranging from diffusion to distillation, extraction to membrane technology, a chemical engineer is required to master mass transfer operations to safely and efficiently design and operate various equipments. Laboratory exercises are integral components of undergraduate education. Through these components, one would gain knowledge through real world experience, as opposed to the theory that is often taught in the class room education. An essential feature of education in science/engineering/technology is that the researcher must have a consensus between theory and practice, or in other words, the philosophical context of the natural phenomena and the practical issues relating to the same.

The undergraduate education is also supposed to unfold the creative component in an individual. Repetitive instruction of the theory without furthering its application could lead to lack of interest in the subject. Therefore, modern education needs to encompass the benefits of both systems of learning i.e., the theoretical way of learning and the practical way of experiencing. This way, one can achieve an amalgamation of both the approaches and consolidate one's own know how of various natural phenomena and technologies developed from these natural phenomena. Thereby, the student will be enabled to awaken his/her creative impetus to serve the growing needs of the society and develop the skills to gradually address more complex problems in chemical engineering.

According to the rapid shifts in societal needs, a student needs to be equipped both with the technical depth and pedagogical skills. To develop a well-equipped lab is a challenge especially for newly founded universities and 
institutes because of the limited budgets. Therefore, virtualization could be beneficial for preliminary learning at a reduced cost.

Repeated experimentation and observation are unique components of research methodologies. Through repeated experimentation/observation, a hypothesis becomes a theory and eventually a law. Therefore, repeated experimentation must be encouraged at all times to inculcate the research component in the younger generation. Repeated experimentation requires man power, human resources, time and patience. Established laws of science/technology need not be repeated several times, but can be simulated. On the other hand, an essential issue that cannot be ignored in undergraduate education is that a student only does one experiment only once in the laboratory, and the experiment may not motivate and impress the student to judge upon the validity of the theoretical issues very seriously.

With this as the central issue in virtualization, IIT Guwahati has been able to develop the virtual mass transfer laboratory under the auspices of Ministry of Human Resource and Development (MHRD) under National Mission on Education through ICT.

\section{Methodology}

\subsection{Development}

After detailed investigation LabVIEW has been identified to be the most effective and efficient platform for virtual mass transfer lab. LabVIEW is an easy to learn, adapt and apply resource. Some of the features include graphical user interface (GUI), built-in engineering-specific libraries of software functions, hardware interfaces; data analysis, and visualization. It allows the user to select their own input values and manipulate them in a manner that resembles to a real laboratory.

\subsection{LabVIEW}

It is a comprehensive development environment that provides engineers and scientists a GUI platform which is easy to use, interact and develop. LabVIEW [1] enables us to acquire, analyze and present the real world data. LabVIEW inspires us to solve problems, accelerate our productivity, and gives us the confidence to continually innovate to create and deploy measurement and control systems. The graphical programming environment i.e., a virtual instrument (VI) consists of two sections: The front panel as shown in Fig. 1 is meant for the user to operate and the block diagram for the developer which accompanies the program developed for the front panel. All the modules are developed using this graphical environment. Randomization procedures which

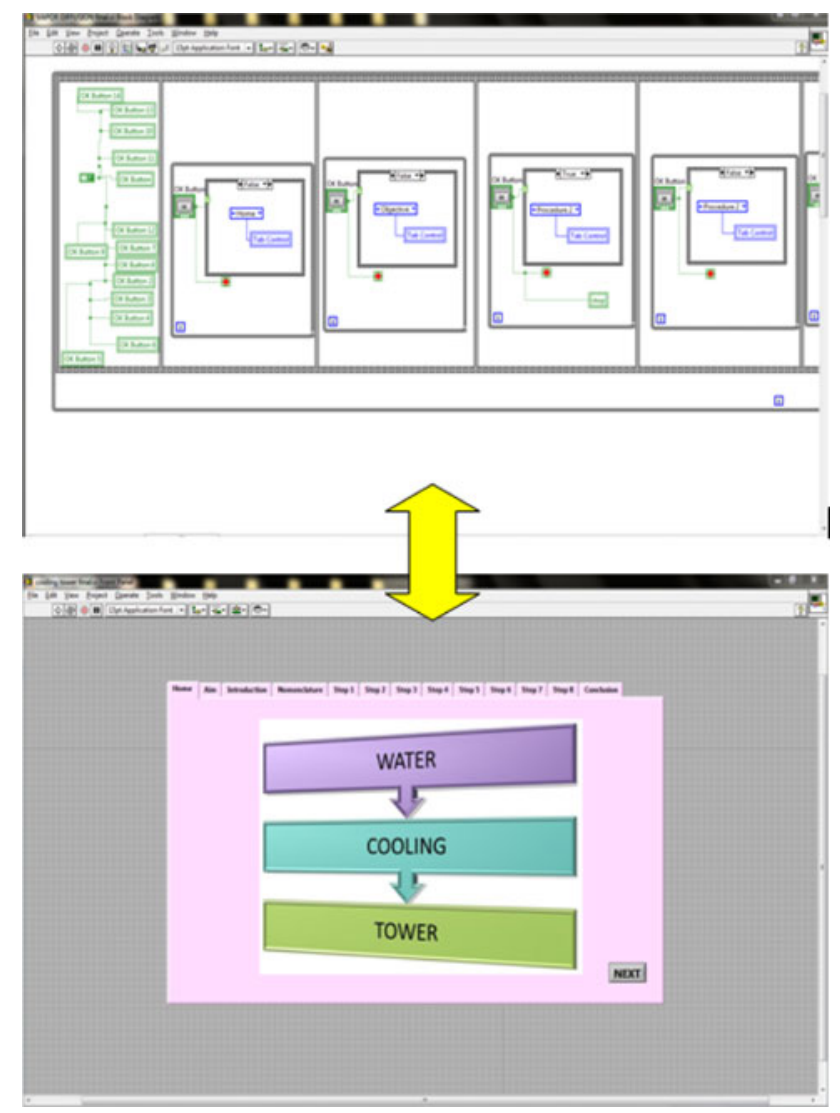

Fig. 1 Block diagram and Front panel

are inbuilt in the software are explored for the development of virtual experiment codes to generate slightly variant data, as observed in real lab experiment. Model experimentation has been targeted from real experiments.

\section{Validation and e-learning enrichment}

\subsection{Experimental investigations}

For each module we with our experts have performed a number of experiments on the apparatus purchased from KC Engineers [2] or fabricated indigenously. After getting a set of repetitive data we compare the obtained experimental data to the standard data available. Then we evaluated the maximum and minimum percentage of error in the experimental data. Finally, embedding the errors along with randomization procedures in the programming environment, the code was developed using the comprehensive development environment LabVIEW. For accessing the LabVIEW code the user has to download the run time engine online [3] and then go to the simulator tab to run and execute the experiment. Videos of the virtual simulator are also available online [4]. The software enables the user 
to select their own input values and manipulate them in a manner that resembles that of a real lab. At the end of the session the code will generate the end result i.e., the virtual data based on the user input.

\section{Modules}

Our aim here is to provide remote-access to some of the general Chemical Engineering labs for catering the needs of students at the undergraduate level, post graduate level as well as to research scholars. In this regard, it is important to note that it is common virtualization misconceptions that virtualization guarantees full understanding. Each module comprises of a no. of segments: simulations, using measurement data from experiments, interactive animations, exciting quizzes, additional web-resources, experimental video-lectures, LabVIEW videos and self evaluation. The virtual laboratory can be also accessed online [4]. The videos for the experiments performed can also be accessed online in the video tab of the website. Quizzes are also inserted in the online portal for the user to visualize what percentage of basic knowledge he/she carries regarding the topic The modules discussed briefly in this paper are Vapor in air diffusion, Flow through porous media, Mass transfer with or without chemical reaction, Binary vapor liquid equilibrium, Column tray efficiency, Forced draft tray dryer, Water cooling tower and Rotary dryer. In the virtual LabVIEW snapshots, the boxes with a green background designate user input/measurements; the boxes with a pink background designate the user's calculated data and the boxes with a blue background designate virtual data. A brief description of various virtual lab modules is presented below.

\subsection{Vapor in air diffusion}

The snapshot shown in Fig. 2a below is the home page of the LabVIEW calculation simulator. On pressing the start button shown in the figure we start with the experimental session. The grey part in the highlighted Fig. 2a designates the various tabs of the experiment. As we move ahead we will see that we are covering tabs after tabs to complete the experiment.

The second tab specifies the objective of the experiment which is as follows:

(a) Determination of the diffusion co-efficient of an organic vapor of carbon tetrachloride in air.

(b) To study the effect of temperature on the diffusion coefficient.

The next tab specifies the experimental setup (shown in Fig. 2b) and the actual experimental procedure which is as follows: (a) Set the water bath temperature at desired level $\left(25-50{ }^{\circ} \mathrm{C}\right)$ and wait till the bath attains the set temperature.

(b) Fill the T-tube with carbon tetrachloride to within $2 \mathrm{~cm}$ of the top of capillary leg. Note down the initial diffusion height of the liquid in the capillary from the top end $\left(\mathrm{X}_{0}\right)$.

(c) Make the connection with the air or vacuum pump and allow a gentle current of air to flow over the capillary.

(d) Record the height of liquid (X) from the top of the capillary tube after every $30 \mathrm{~min}$.

(e) Repeat the steps (a)-(d) for different temperatures.

(f) Plot diffusion co-efficient against absolute temperature on a log-log graph and determine the slope. It should lie between 1.5 and 1.8 .

The next few tabs specify the virtual LabVIEW procedure which is to be used by the user to complete the experiment:

Step 1 This step consists of a flowsheet (shown in Fig. 2c) describing the entire virtual process and comprising of all suitable formulas required to complete the calculations. The user will have to follow all the steps starting from vapor pressure [5, 6] calculation to diffusion co-efficient calculation.

Step 2 Here starts the actual virtual experiment. In this step, the user has to first select a suitable value for temperature and accordingly the user has to calculate the vapor pressure and corresponding carbon tetrachloride concentration data using the mentioned formulas in the flowsheet shown in Fig. 2c.

Step 3 The next six tabs are similar sets of virtual experiments consisting of user inputs and virtual outputs but are carried at different operating conditions. Here the input is time, initial main scale reading and the vernier scale reading. Time ought to be varied after each run whereas the scale reading should be kept constant. Virtually the actual scale readings depending on the input time are being generated by the code as shown in Fig. 2d below.

Step 4 After the completion of six set of virtual experiment, the user has to calculate the slope of a graph between $t /\left(x-x_{0}\right)$ against $\left(x-x_{0}\right)$ where $t$ corresponds to time and $\left(\mathrm{x}-\mathrm{x}_{0}\right)$ corresponds to drop in liquid level at time $\mathrm{t}$ and the diffusion co-efficient using the virtual data. Finally the user is asked to enter those calculated values in the space provided with a pink background.

Step 5 The next tab is basically meant for comparison. All the standard and virtual data including the final virtual diffusion co-efficient data will be automatically displayed in this step. The user has to enter his/her 


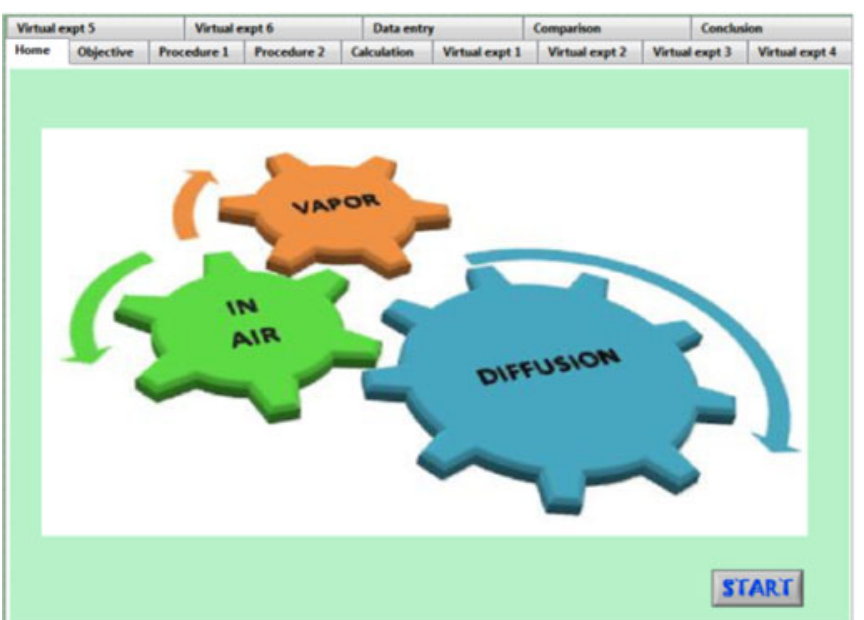

(a)

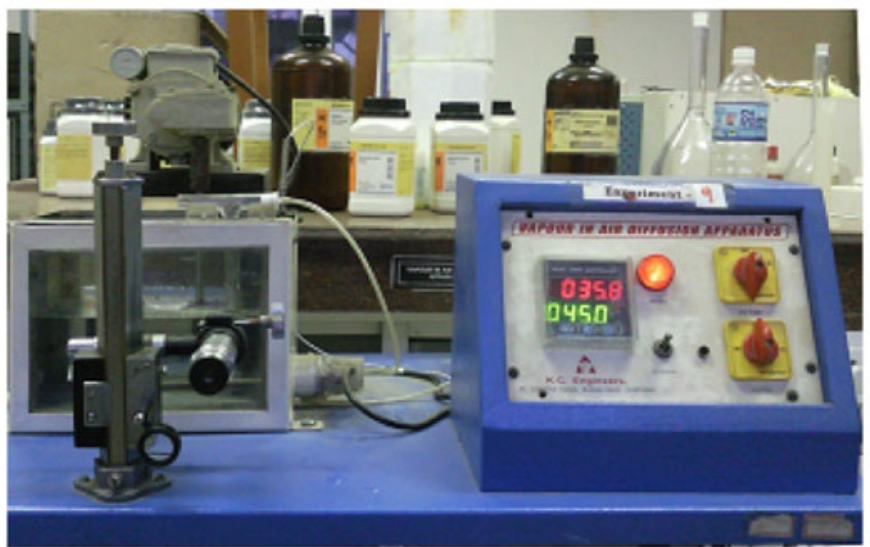

(b)

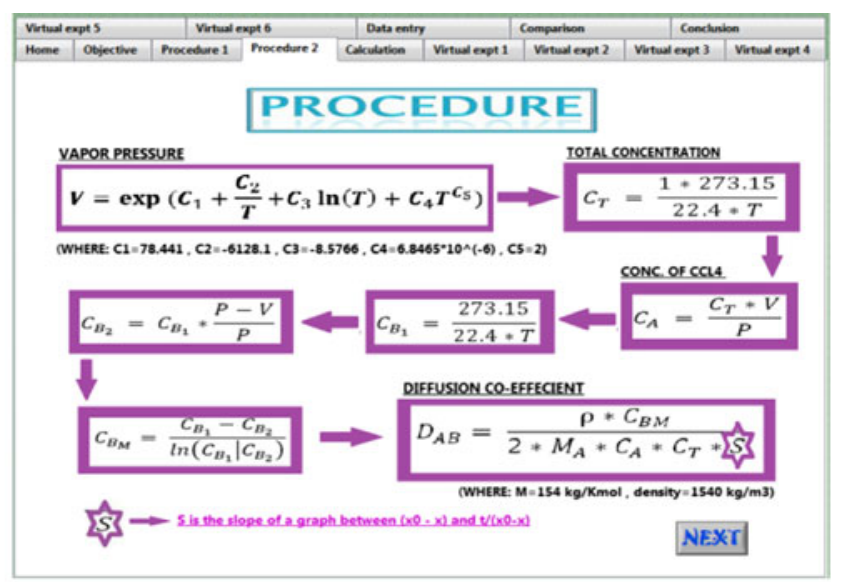

(c)

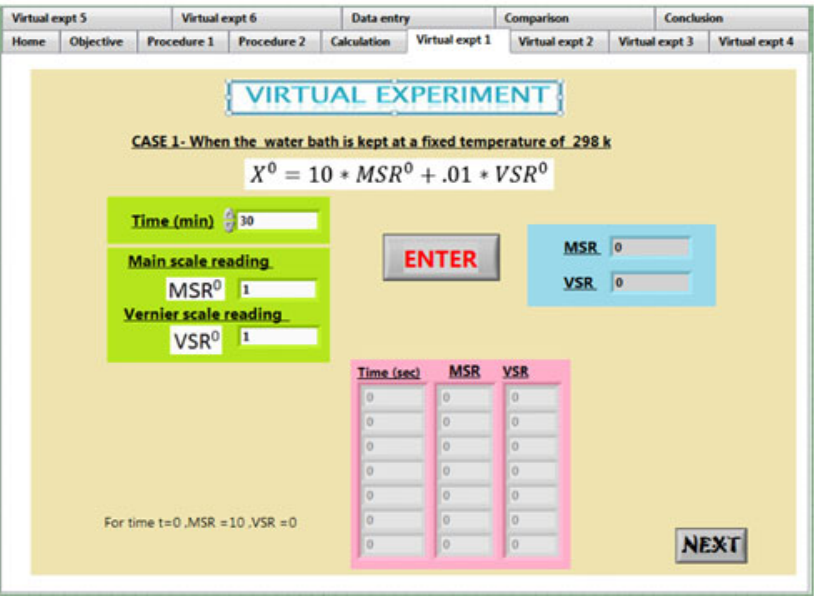

(d)

Fig. 2 a Home page for vapor in air diffusion module; b experimental setup for vapor in air diffusion module; c virtual LabVIEW procedure for vapor in air diffusion module; $\mathbf{d}$ virtual LabVIEW setup for vapor in air diffusion module

calculated diffusion co-efficient values and then compare that with the virtual data. This step enables the user to know how much he/she is deviating from the virtual and the standard data.

Step 6 This is the concluding step of the experiment which gives the user possible reasons of deviation from the actual data.

\subsection{Flow through porous media}

The objective of this experiment is to study the membrane support and membrane flow properties [7]. On pressing the start button in the home page of the LabVIEW calculation simulator we start with the experimental session. As we move ahead we will see that we are moving tabs after tabs to complete the experiment.

The second tab gives a general overview about membranes and the procedure as mentioned: A membrane is a layer of material which serves as a selective barrier between two phases and remains impermeable to specific particles, molecules, or substances when exposed to the action of a driving force. Knudsen diffusion and solution diffusion are prominent mechanisms. Knudsen diffusion is a means of diffusion that occurs in a long pore with a narrow diameter $(2-50 \mathrm{~nm})$ because molecules frequently collide with the pore wall. The transport of gases through dense (nonporous) polymer membrane occurs by a solution diffusion mechanism. The gas dissolves in the polymer at the high pressure side of the membranes, diffuses through the polymer phase, and desorbs or evaporates at the low pressure side.

The next tab dictates the experimental procedure as stated:

- The setup constitutes a Teflon tubular cell with a flat circular Teflon base plate that houses the ceramic membrane. 
- The membrane was kept in the Teflon casing and sealed with epoxy resin.

- The outlet of the setup was connected to a gas flow meter using a silicon tube for measuring the gas flow rate at various trans-membrane pressure differentials.

The next few tabs specify the virtual LabVIEW procedure which is to be used by the user to complete the experiment.

Step 1 This step (shown in Fig. 3a) demonstrates the flow sheet for membrane support properties calculations. The flow sheet shown in the snapshots clearly defines the formulas and the steps for the calculation of membrane support properties in terms of average pore radius and porosity starting with pressure as user input.

Step 2 The next tab similarly demonstrates the flow sheet for membranes film property calculations. It clearly designates the formulas and the steps for the calculation of membrane film properties in terms of average pore radius, permeability factor and porosity.

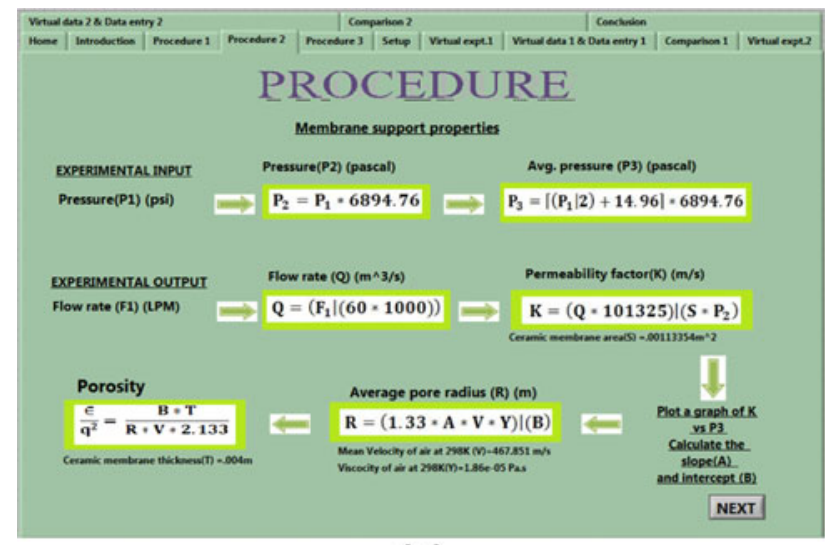

(a)

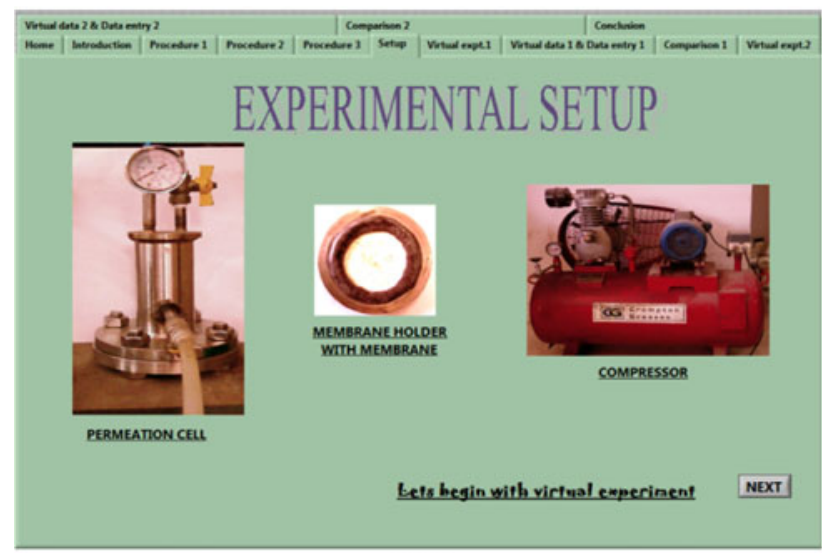

(b)

Fig. 3 a Virtual LabVIEW procedure for flow through porous media; b experimental setup for flow through porous media
The next tab features the actual experimental setup consisting of the permeation cell, membrane holder and the compressor as shown in the Fig. $3 \mathrm{~b}$ below.

Step 3 This tab provides the user to interact and learn the calculations thus enabling the user with a feel of real experiment. This tab focuses on the first case for the calculation of support properties. For this step pressure is the input which the user has to fix and flow rate and permeability factor $(k)$ are the virtual output which the code will generate.

Step 4 In the next tab based on the virtual outputs of previous step the user has to calculate the slope and intercept of a graph between permeability factor $(\mathrm{k})$ and average pressure, pore radius and porosity using suitable formulas provided in the flowsheet shown in Fig. 3a.

Step 5 This step covers the comparison between the user's data and the virtual data. All the virtual data calculated will also be displayed to the user for his/her assessment. Step 6 From this step we start with the calculation of membrane film properties. For this step pressure is the input and flow rate and permeability factor $(\mathrm{k})$ are the virtual output.

Step 7 In the next tab the comparison is done for membrane film properties. Based on the virtual outputs of previous step the user has to calculate the slope and intercept, of a graph between permeability factor $(\mathrm{k})$ and average pressure, pore radius and porosity using suitable formulas.

Step 8 The next tab indicates the comparison between the user's data and the virtual data for the membrane film property determination.

Step 9 Finally the concluding tab of the experiment is assessment which gives marks to the user based on his performance in the previous steps.

\subsection{Mass transfer with or without chemical reaction}

The objective of this experiment is:

(a) To Study the dissolution of benzoic acid in aqueous $\mathrm{NaOH}$ solution.

(b) To compare the observed enhancement factor for mass transfer with those predicted by film and boundary layer model.

(c) Mass transfer with chemical reaction (solid-liquid system): Dissolution of benzoic acid in aqueous $\mathrm{NaOH}$ solution.

Solid-liquid mass transfer plays an important role in some industrial operations. The dissolution may occur with or without chemical reaction. In case dissolution is accompanied by solid-liquid reaction, it is desirable to know the enhancement in the rate of mass transfer due to 
simultaneous reaction and compare it with the enhancement predicted on the basis of the film and the boundary layer models. Here the system under study is dissolution of benzoic acid in aqueous $\mathrm{NaOH}$ solution.

The experimental setup shown in Fig. 4a consists of a cylinder of benzoic acid mounted on a stainless steel rod and with a D.C. motor. The operational range of rotation is between 10 and $30 \mathrm{rpm}$. The cylinder is immersed in an aqueous solution of sodium hydroxide of known concentration in a $500 \mathrm{ml}$ vessel filled to two-third its capacity. The position of the benzoic cylinder is so adjusted that the liquid level rises above the top surface by about the top surface by about $3 \mathrm{~cm}$. The dimensions of the benzoic acid may be fixed at diameter 2 or $3 \mathrm{~cm}$, length $5-7 \mathrm{~cm}$ the cylinder can be prepared by pouring molten benzoic acid in the mould of desired dimensions with $4-5 \mathrm{~mm}$ stainless

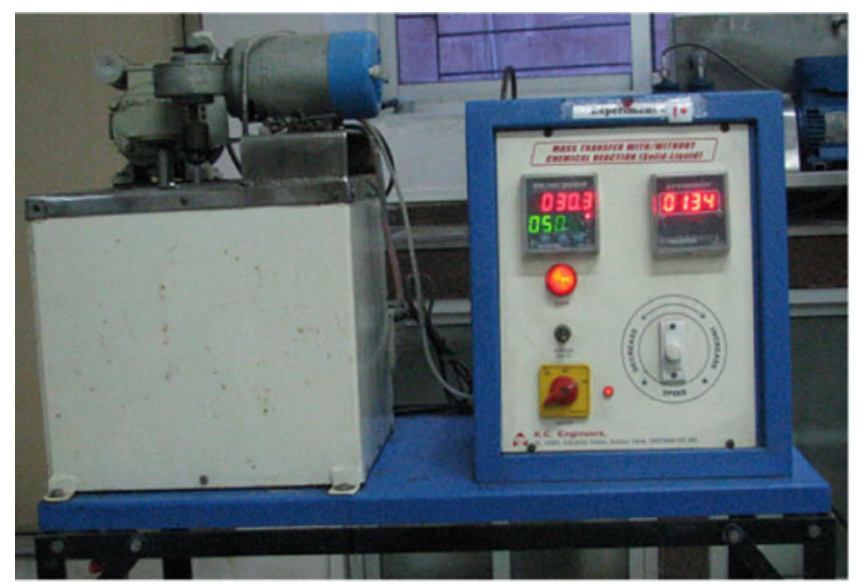

(a)

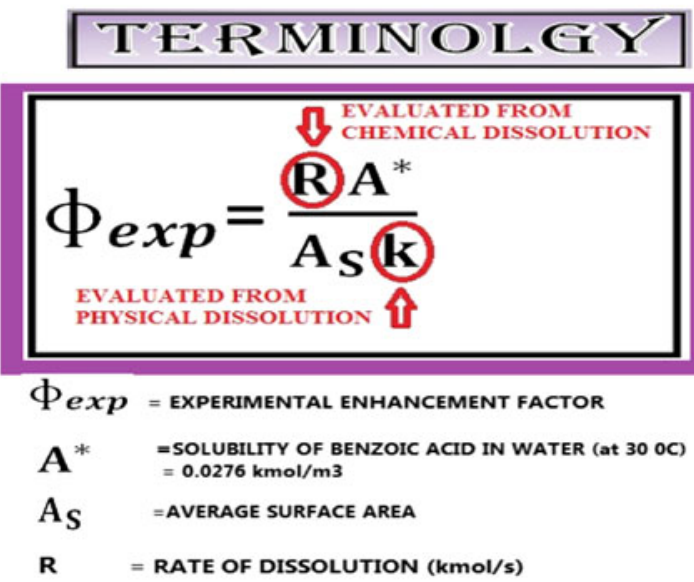

The unit of $\mathrm{k}$ is $\mathrm{m}$.

(b)

Fig. 4 a Experimental setup for mass transfer with or without chemical reaction; b terminology for mass transfer with or without chemical reaction module; c virtual LabVIEW chemical dissolution steel rod located in the center of the mould in a vertical position.

The actual procedure is as follows:

(a) Record the dimensions of the benzoic acid cylinder (Outer diameter, length of acid cylinder and outer diameter of stainless steel rod) and then fix it in a vertical position with the D.C. motor.

(b) Fill the vessel with aqueous $\mathrm{NaOH}$ solution of known concentration up to $2 / 3 \mathrm{rd}$ of its volume. Record the volume of aqueous $\mathrm{NaOH}$ solution added (v).

(c) Start the water bath and fix the dissolution temperature, ambient up to $50{ }^{\circ} \mathrm{Celsius}$.

(d) Fix the benzoic acid cylinder inside the vessel containing aqueous $\mathrm{NaOH}$ solution and start the motor at a fixed rotational speed $\mathrm{N} \mathrm{rpm}$.

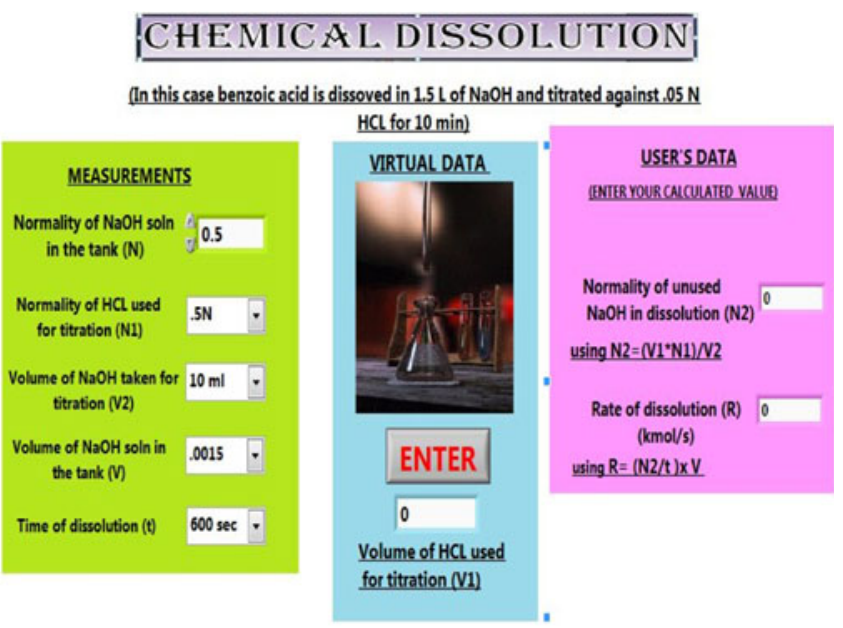

(c)
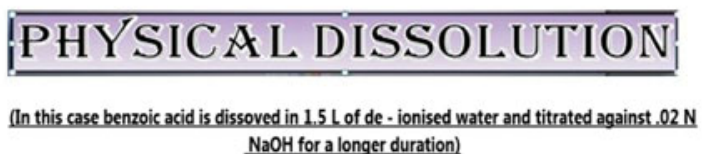
$\mathrm{NaOH}$ for a longer duration)

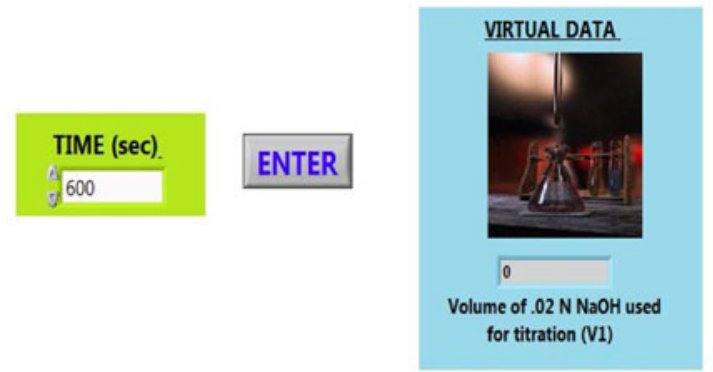

NOTE:

1. Now we can calculate Ab i.e. the bulk liq cons of benzoic acid by using $\mathrm{N} 2=\left(\mathrm{N} 1{ }^{*} \mathrm{~V} 1\right) / \mathrm{N} 2$ Where $\mathrm{N} 1=02 \mathrm{~N}$ and $\mathrm{V} 2=10 \mathrm{ml}$. 2. Solubility of benzoic acid in water $A^{*}=0.0276 \mathrm{kmol} / \mathrm{m} 3$. 3.A graph is plotted betweem time $\mathrm{vs} \ln \left(1-\mathrm{Ab} / \mathrm{A}^{*}\right)$ and then by using linear regression the slope is evaluated.

(d)

setup for mass transfer with or without chemical reaction module; $\mathbf{d}$ virtual LabVIEW physical dissolution setup for mass transfer with or without chemical reaction module 
(e) Run the experiment for $10 \mathrm{~min}$.

(f) Stop the motor and remove benzoic acid cylinder and measure its dimensions again.

(g) Mix thoroughly the contents of the vessel and analyze it for unreacted $\mathrm{NaOH}$ concentration by titration against standard $\mathrm{HCl}$ solution.

(h) Measure the benzoic acid cylinder dimensions again.

(i) Repeat the above steps for different concentrations of aqueous $\mathrm{NaOH}$ solutions.

(j) Repeat the above steps using de-ionised water. This run may be carried for about 45-60 min duration. During this period small samples should be withdrawn at regular intervals of $10 \mathrm{~min}$ and analyzed for dissolved benzoic acid by titration against $0.02 \mathrm{kmol} /$ $\mathrm{m}^{3} \mathrm{NaOH}$ solution.

The entire virtual procedure consists of two parts:

(a) Chemical measurements (titration)

(b) Physical measurements (dimensions)

The terminology for the experiment is as highlighted in Fig. 4b.

The next few tab features the virtual LabVIEW procedure which is to be followed by the user to complete the experiment.

Step 1 In this step physical measurements for initial length and initial diameter of the benzoic acid cylinder are to be entered by the user.

Step 2 This step is the chemical dissolution step. In this step virtually titration is carried for a case where benzoic acid is dissolved in $1.5 \mathrm{~L}$ of $\mathrm{NaOH}$ and titrated against $0.05 \mathrm{~N} \mathrm{HCl}$ for $10 \mathrm{~min}$. The snapshot shown in Fig. 4c clearly specifies the measurement which is to be fixed by the user, the virtual data for the titration which the code will deliver and based on the virtual data the user will calculate his data and enter in the space provided with a pink background.

Step 3 The next step covers the physical dissolution part. In this step (shown in Fig. 4d virtually titration is carried for a case where benzoic acid is dissolved in $1.5 \mathrm{~L}$ of deionized water and titrated against $0.02 \mathrm{~N} \mathrm{NaOH}$. For different period of time which the user will input the code will generate virtual data for volume of sodium hydroxide used for titration.

Step 4 In this step the user will determine the average surface area and specific rate of dissolution. The final length and diameter of the cylinder is virtually displayed for the given user inputs in step 1.

Step 5 In this step we determine the experimental $\emptyset$ value and the values for $\varnothing$ film and $\varnothing$ boundary are virtually generated and displayed by the code.

Step 6 The next tab indicates the comparison between the user's data and the virtual data for average surface area, specific rate of dissolution and phi experimental values.

Step 7 Finally the concluding tab of the experiment is assessment which gives marks to the user based on his performance in the previous steps thereby specifying the possible reasons for errors or deviation from the virtual data.

\subsection{Binary vapor liquid equilibrium}

The objective of this experiment is to determine the composition of components in vapor phase and plot graph between temperature and mole fraction and to determine the relative volatility.

Equilibrium is a static condition in which no changes occur in the macroscopic properties of a system with time. Vapor liquid Equilibrium is a condition where a liquid and its vapor are in equilibrium with each other, a condition or state where the rate of evaporation is equal to the rate of condensation one a molecular level such that there is no overall vapor liquid inter-conversion [8]. Relative volatility is a measure of comparing the vapor pressures of the components in a liquid mixture of chemicals. The experimental setup is shown in Fig. 5a below.

The actual experimental procedure is as stated:

- The setup consists of a round bottom flask, a condenser, a thermocouple, two water streams, a heater and a conical flask.

- A mixture of benzene and toluene is prepared and put into the flask. Then the power is supplied and the mixture begins to boil.

- After some time equilibrium is reached, this is marked by steady temperature in both the phases.

- Samples of condensed vapor and liquid are taken. To calculate the composition we need to measure the refractive index of the sample.

In an experiment since vapor and liquid composition changes dynamically we need to measure until they reach vapor liquid equilibrium. For such a measurement, physical properties (such as refractive index) can be explored and related to the composition of a liquid.

The entire virtual procedure in depicted below with the help of suitable snapshots and steps.

Step 1 The first step involves the calibration part where the user input is volume fraction and the virtual output is the corresponding refractive index value which the code will generate depending on the input.

Step 2 The next step includes the experiment part where the input is volume fraction and the output which the user virtually gets are the temperatures and the refractive index. 
Step 3 This step enables the user to calculate the equilibrium compositions in the vapor and liquid phase from the refractive index data which he/she got in step 2 . Step 4 In this step the user has to calculate the relative volatility by using his/her equilibrium composition values which they have previously calculated in step 3. Finally they need to give an average relative volatility value.

Step 5 In this step the virtual equilibrium compositions data in the vapor and liquid phase will be displayed and parity plots between user's equilibrium composition and virtual equilibrium composition will be generated by the code as shown in Fig. 5b.

Step 6 This is the last step which tells the user all possible reasons of deviating from the standard value of relative volatility.

\subsection{Column tray efficiency}

The objective of the experiment is to study the operation of a batch rectification column under constant or total reflux condition. In a batch rectification setup vapors generated in the kettle pass up the column counter currently to the liquid that is passing down the column. The column packing provides a good contact between the liquid and the vapor. As liquid passes up the column, it comes in contact with thin film of liquid formed around the packing surface. The experimental setup is as shown in Fig. 6a below:

The experimental procedure is as follows:

- Charge the still with $2 / 3$ of methanol-water feed mixture.

- Record the exact feed composition $\left(\mathrm{x}_{\mathrm{F}}\right)$ from the calibration curve by using a refractometer.
- Start the supply to the condenser and switch on the heat supply to the still.

- Operate the column under total and partial reflux conditions and adjust the heat input to the still till the temperature in the still is ready.

- Read the temperature at the top and the bottom until they indicate that the system has reached equilibrium.

- At steady state record the composition of the distillate and the still liquid.

The entire virtual procedure in depicted below with the help of suitable steps.

Step 1 It includes the calibration part where the user will get the virtual data for refractive index on inserting the mole fraction data and pressing enter. Ten such different values are to be inserted in order to complete the step.

Step 2 In the next step all the data entered by the user and the virtual data will be displayed. Accordingly in this step the user is asked to plot a graph between refractive index and mole fraction and calculate the slope of the graph for further calculations.

Step 3 In this step the user is asked to input the reflux and feed composition values and the code will virtually generate the refractive index (RI) value for both partial and total reflux as shown in Fig. 6b.

Step 4 In this step the user has to enter his calculated values of efficiency and number of equilibrium stages based on the virtual data obtained from step 3 .

Step 5 This is a simple comparison step between the user's calculated data and the virtual data obtained so far. It consists of efficiency and number of equilibrium stages data comparison for both partial and total reflux case.

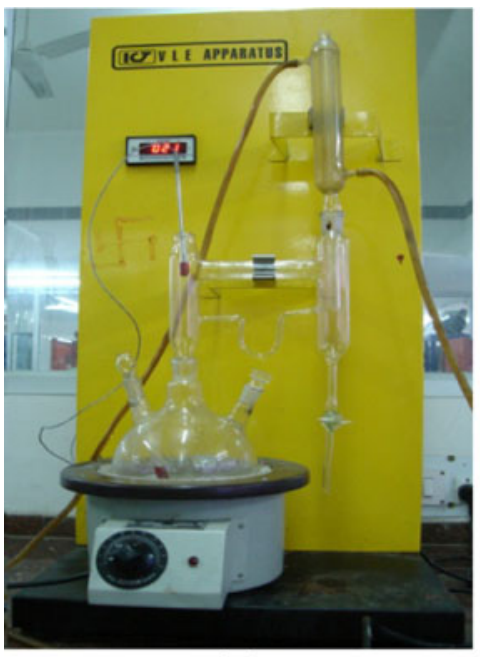

(a)
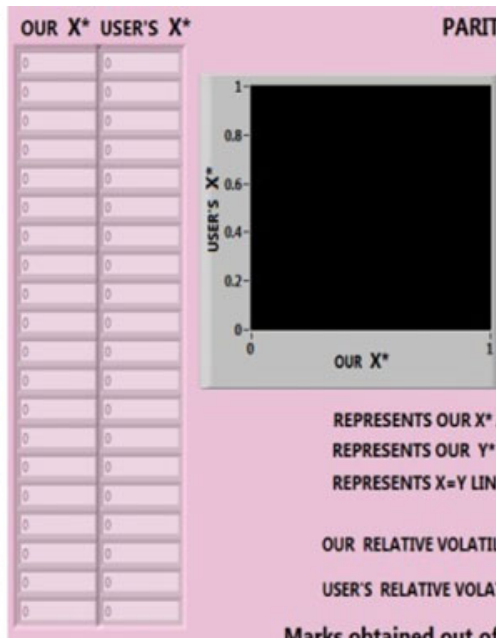

ARTYY PLOTS

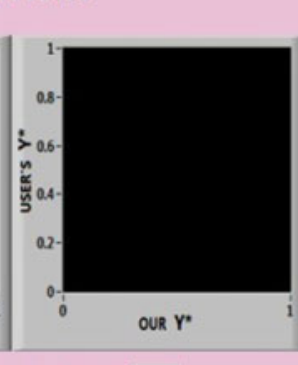

REPRESENTS OUR $X^{*}$ AND USER' $S X^{*}$ REPRESENTS OUR ${ }^{*}$ AND USER' $S{ }^{*}$ REPRESENTS $X=Y$ UINE

OUR RELATIVE VOLATIUTY

USER'S RELATIVE VOLATIUTY

Marks obtained out of 10 :

(b)

Fig. 5 a Experimental setup for binary vapor liquid equilibrium; b virtual LabVIEW setup for binary vapor liquid equilibrium 


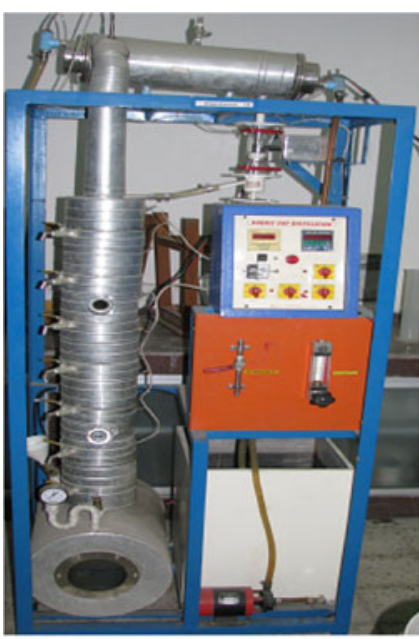

(a)

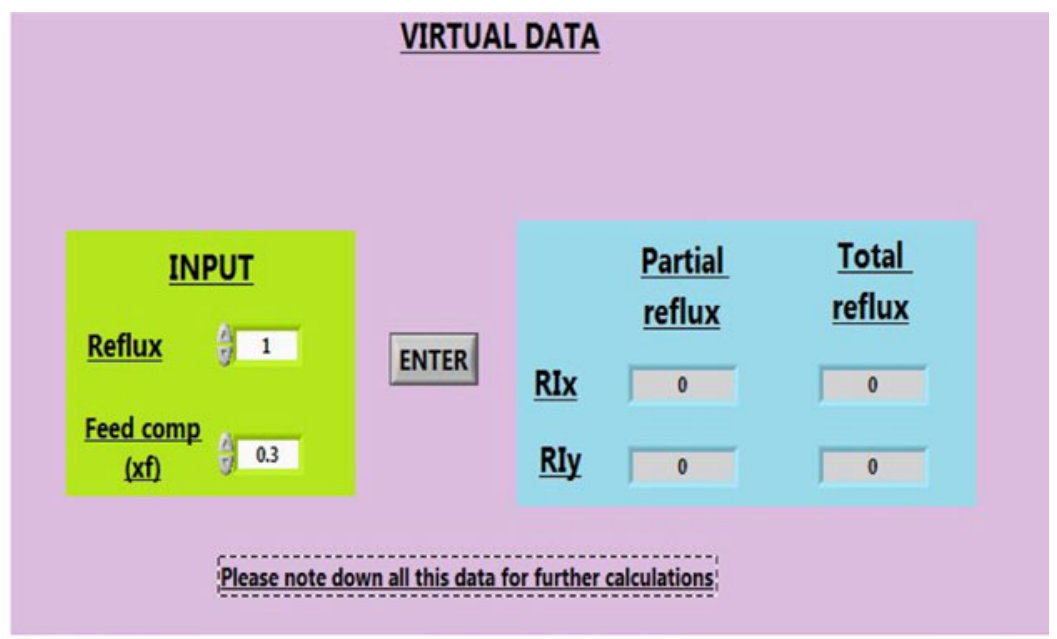

(b)

Fig. 6 a Experimental setup for column tray efficiency module; b virtual LabVIEW setup for column tray efficiency module

Step 6 This is the last and the concluding step mentioning the marks the user gets on his/her performance. This step enables the user to assess his/her percentage of deviation from the virtual data.

\subsection{Forced draft tray dryer}

The objective of this experiment is to study the drying characteristics of a solid under forced draft condition. Drying of solids is considered to occur in two stages, a constant rate period followed by a falling rate period. In the constant rate period the rate of drying corresponds to the removal of water from the surface of solid. The falling rate period corresponds to the removal of water from the interior of the solid [5]. The rate in either case is dependent on flow rate of air, the solid characteristics, tray material. The experimental setup (shown in Fig. 7a) with a brief description of the procedure is as follows:

- Load the pre-weighed tray with solid and place it over the balance in the drying chamber.

- Record the weight of sand and tray.

- Start the blower and fix the air flow rate and also its inlet temperature by adjusting the energy regulator.

- When the desired conditions of temperature and air velocity are reached, remove the sample tray and put known amount of water in it to give desired initial moisture content.

- Keep the tray gently in the drying chamber and start the stop watch. Record the balance reading with time at about 3-5 min interval.

- Drying is assumed to be complete when at least 3 consecutive readings are unchanged.
- The same steps are repeated for other runs at different operating conditions.

The entire virtual procedure in depicted below with the help of suitable steps.

Step 1 This is the first step where the user is asked to fix the moisture content (i.e. water in $\mathrm{ml}$ ) for the experiment.

Step 2 In the next step three sets of virtual experiments are carried on at different operating conditions. Here the user input is time and the output which the user virtually gets is the weight of the dried solid. Using this weight, moisture content $(\mathrm{X})$ is calculated as shown in Fig. 7(b). Step 3 In this step the user is asked to find out the slope for time (t) Vs moisture content $(\mathrm{X})$ graph, and finally calculate the drying rate $(\mathrm{N})$. The user has to enter his/ her calculated values in the space provided.

Step 4 it is the self-assessment part where the user has to match his obtained data with some standard plot available. Step 5 It is the second self-assessment part where the user has to see to which trend his/her graph follows. Based on his/her trend the user will also get marks which will enable the user to know how much he/she is deviating from the virtual data.

Step 6 This step consist of the cost calculation part. Here the inputs are pressure and time of drying which the user will fix and accordingly he/she will get the virtual data for mass flow rate, cost and cost/weight as shown in Fig. $7 \mathrm{c}$.

Step 7 This step involves the third assessment where we basically focus on the cost. Accordingly the user has to select what factors would be profitable for a desirable setup. 


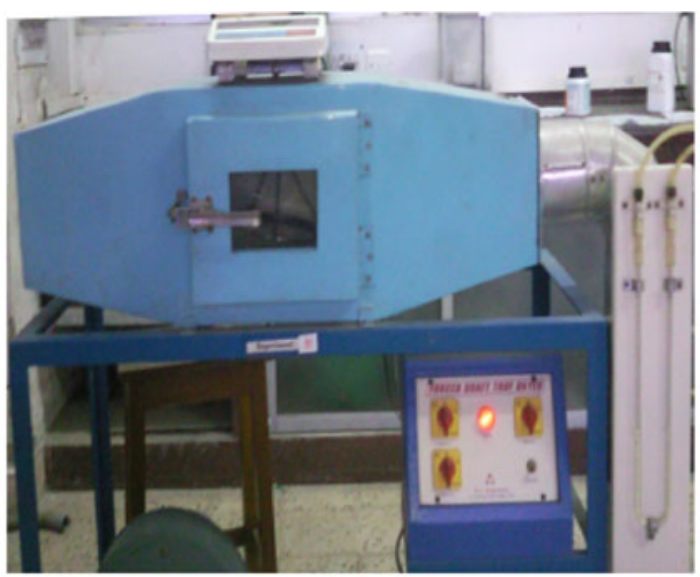

(a)

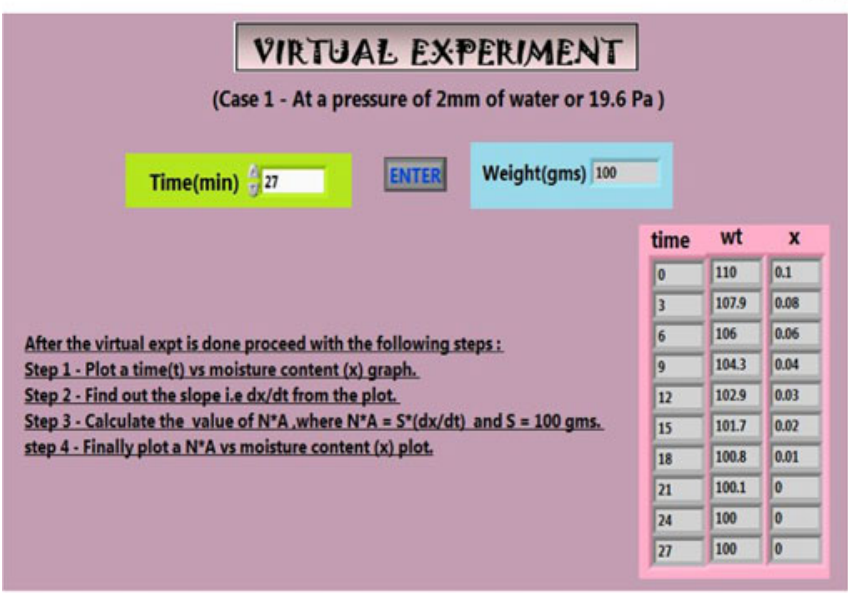

(b)

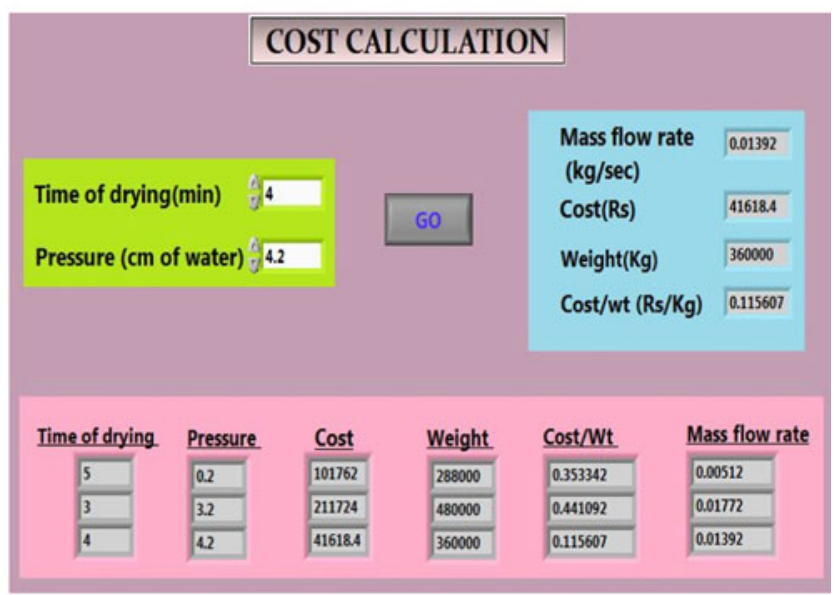

(c)

Fig. 7 a Experimental setup for forced draft tray dryer; b virtual LabVIEW experimental setup for forced draft tray dryer; c virtual LabVIEW cost calculation setup for forced draft tray dryer

Step 8 Finally this step is the concluding step where the user comes to know possible reasons of deviation from the standard data.

\subsection{Water cooling tower}

The objective of this experiment is to determine the overall heat transfer coefficient in a forced draft counter current cooling tower and to measure tower characteristic parameter $\mathrm{KV} / \mathrm{L}$ for various liquid and air flow rates $(\mathrm{L} / \mathrm{G})$ in a counter-current forced draft cooling tower [8].

Water from condensers and heat exchangers is usually cooled by an air stream in spray ponds or in cooling towers using natural draft or forced flow of the air. Mechanical draft towers are of the forced draft type, where the air is blown into the tower by a fan at the bottom. The forced draft materially reduces the effectiveness of the cooling. The experimental setup is shown in Fig. 8a.
The experimental procedure is as follows:

- Fill the heating tank with water, set the temperature and switch on heater.

- Switch on pump and blower after desired temperature achieved. Set the flow rate of water and air.

- Record the flow rate of water and manometer reading after steady state achieved. Record the temperatures.

- Steps 3 may be repeated for different water and air flow rates within operational range.

The entire virtual procedure in depicted below with the help of suitable steps.

Step 1 In this step (shown in Fig. 8b) the user is asked to fix the input values for diameters of the orifice and pipe, co-efficient of discharge and densities of manometer fluid and air. Based on that data the user has to calculate the cross sectional area of the pipe and the orifice and enter the values in the box provided. 


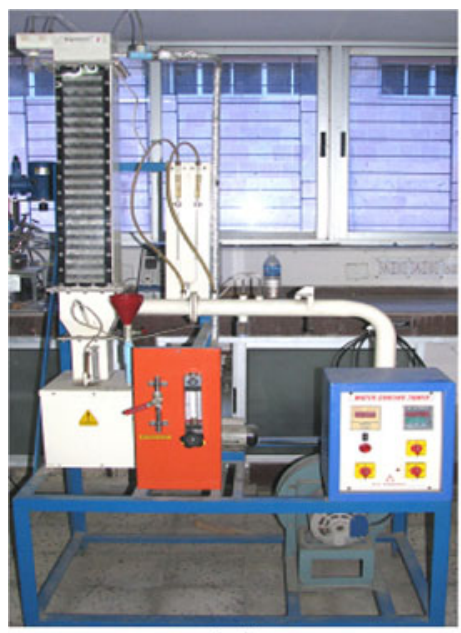

(a)

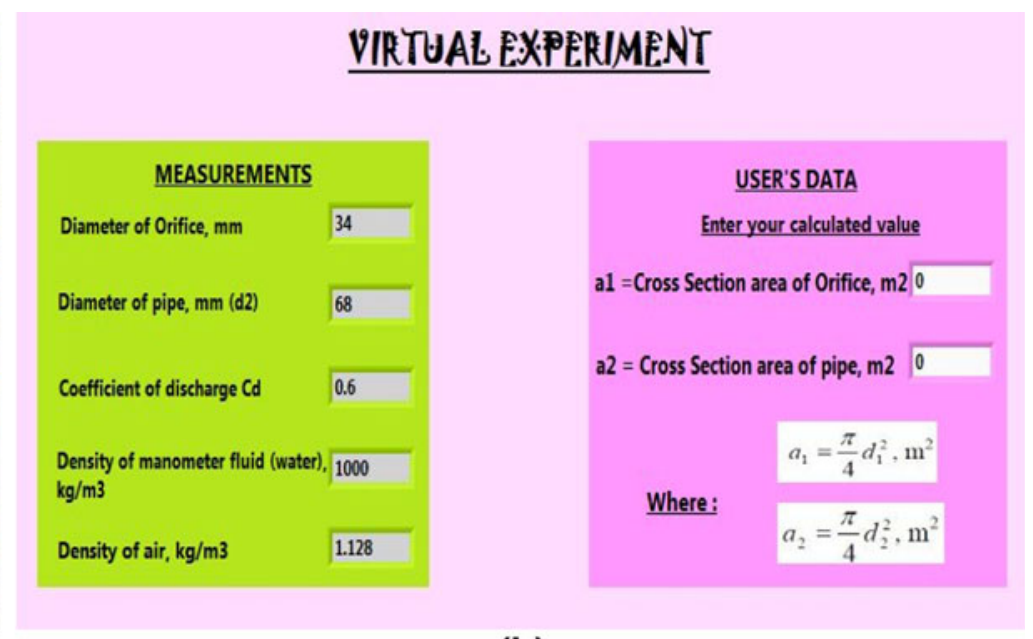

(b)

Fig. 8 a Experimental setup for water cooling tower; b virtual LabVIEW setup for water cooling tower

Step 2 In the next step the user will be supplied with virtual data for temperature, water levels and flow rate which the user will require for further calculations.

Step 3 Then the user will have to enter his calculated values based on the virtual data and formulas provided. Step 4 Here the user will have to enter his calculated values for the volumetric flow rate $(\mathrm{Q})$ of the fluid, air flow rate $(\mathrm{G})$ and the liquid flow rate $(\mathrm{L})$ based on the virtual data and suitable formulas provided.

Step 5 In this step the user will be provided with virtual data for temperature and enthalpy.

Step 6 Here the user will have to enter his calculated value for the enthalpy $\left(\mathrm{h}_{\mathrm{a}}\right)$ based on the virtual data provided by the code.

Step 7 In this step the user has to enter his calculated value for the tower Characteristic parameter.

Step 8 This is a simple comparison step between the user's calculated data and the virtual data generated by the code. Step 9 This is the self-assessment step which declares the marks the user gets based on his performance throughout the experiment.

\subsection{Rotary dryer}

The objective of this experiment is to determine the drying characteristic for rotary dryer.

The rotary dryer is a type of industrial dryer employed to reduce or minimize the liquid moisture content of the material by bringing it in direct contact with a heated gas [9]. The dryer is made up of large rotating cylinder which slopes slightly so that the discharged end is lower than the material feed end in order to convey the material under gravity. Material to be dried enters the dryer and as the dryer rotates, the material is lifted up by a series of internal fins lining the inner wall of the dryer. When materials fall back to the bottom, it passes through the hot gas stream. In the experiment, the gas stream moves towards the feed end from the discharge end (counter current flow). Also the material passes through the length of the dryer at nearly the wet-bulb temperature. The experimental setup is shown in Fig. 9a.

The experimental procedure is as follows:

- Set the pre-heating temperature for air.

- Fill the feed hopper with wet solid.

- Measure the initial moisture content of the feed.

- Start the dryer in rotary motion.

- Allow the wet solid to flow through the dryer by starting the screw conveyor at the pre fixed speed.

- At steady state record the following:

(a) Air flow rate (Orifice meter, manometer reading and convert it to volumetric flow rate and mass flow rate) $=\mathrm{G}_{\mathrm{G}}$

(b) Air temperature at inlet $=\mathrm{t}_{\mathrm{G} 1}$

(c) Air temperature at outlet $=\mathrm{t}_{\mathrm{G} 2}$

- Repeat the above steps for at least four different gas flow rates.

The entire virtual procedure in depicted below with the help of suitable snapshots.

Step 1 In this step pressure is the user input and the inlet and outlet temperatures are the output which the code virtually displays.

Step 2 The next step (shown in Fig. 9b) is the calculation part where by using the input values of step 1 and some suitable formulas the user has to calculate the volumetric flow rate, mass flow rate and the air mass velocity. All this calculated values are to be inserted in the space provided with a pink background. 


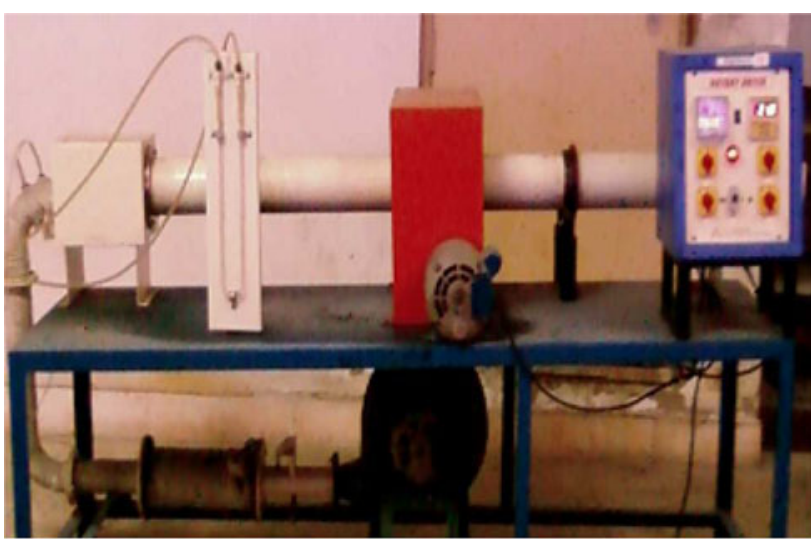

(a)

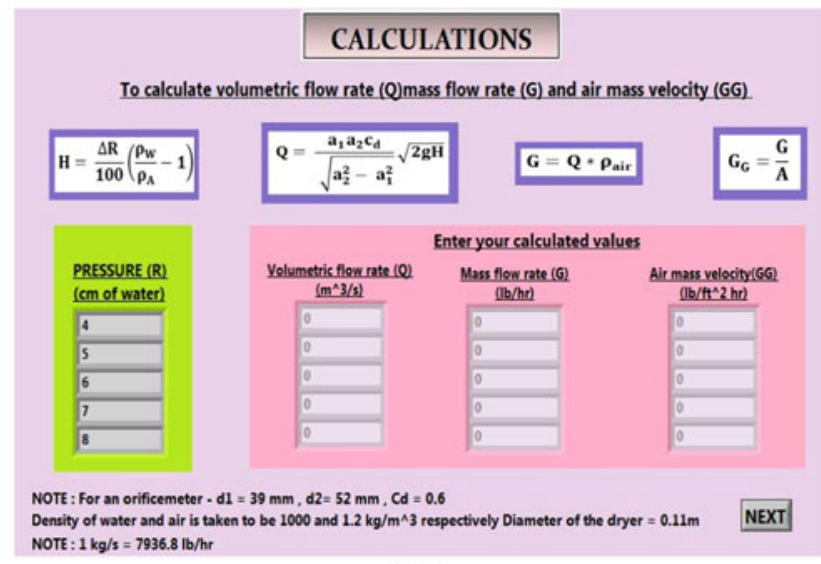

(b)

Fig. 9 a Experimental setup for rotary dryer; b virtual LabVIEW Setup for rotary dryer

Step 3 In this step the user has to calculate the overall heat transfer co-efficient using the virtual temperature data which the user got in step 1.

Step 4 This step basically includes comparison between the calculated user's data and the virtual data for air mass velocity and overall heat transfer co-efficient.

Step 5 This is the final step which concludes the experiment by giving marks on the user's capability to perform the calculations correctly.

\section{Confidence levels and benchmarks}

\subsection{Simulation versus experiment}

(i) Experimental/simulator calculations for the vapor in air diffusion module: experimental data for the vapor in air diffusion module has been presented below in Table 1.Now we plot a graph between $\left(\mathrm{x}-\mathrm{x}_{0}\right)$ and time/( $\left.\mathrm{x}-\mathrm{x}_{0}\right)$.

The straight line in Fig. 10a signifies the standard data trend and the dotted line signifies the experimental/ simulated data. With this experimental/simulated data further calculations have been carried on using standard formulas and procedures.

(ii) Experimental/simulator calculations for the forced draft tray dryer module: Experimental data for the forced draft tray dryer module has been presented in Tables 2 and 3.

At Pressure $=1.5 \mathrm{~cm}$ of water

Weight of dry solid, $\mathrm{S}=100 \mathrm{~g}$

Amount of initial moisture $=15 \mathrm{ml}$

Weight of solid, $\mathrm{W}=$ solid + water

Moisture content present in solid,

$\mathrm{X}=(\mathrm{W}-\mathrm{S}) / \mathrm{S}$

We have the experimental data as in Table 2.

Now we plot a $X$ versus $t$ plot as shown below in Fig. 10b. From this plot we calculate the

Slope $=-\mathrm{dx} / \mathrm{dt}$.

Now we have the drying rate as

$\mathrm{N}=-\mathrm{S} \frac{\mathrm{dx}}{\mathrm{dt}} \frac{1}{\mathrm{~A}}$

For a constant area we have the drying rate equation as:

$\mathrm{N}=-\mathrm{S} \frac{\mathrm{dx}}{\mathrm{dt}}$

Thus we have the Experimental data as in Table 3.

Finally we plot a graph between $\mathrm{X}$ versus $\mathrm{N}$ as shown in Fig. 10c:

The same steps are repeated for other runs at different operating conditions.

(iii) Experimental/simulator calculations for the flow through porous media module: experimental data

Table 1 Experimental data for vapor in air diffusion module

\begin{tabular}{llll}
\hline Time, $\mathrm{s}$ & Liquid level $\mathrm{x}(\mathrm{mm})$ & $\left(\mathrm{x}_{0}-\mathrm{x}\right)(\mathrm{mm})$ & $\mathrm{t} /\left(\mathrm{x}_{0}-\mathrm{x}\right)(\mathrm{s} / \mathrm{mm})$ \\
\hline 0 & $\mathrm{x}_{0}=62.75$ & 0 & - \\
900 & 62 & 0.75 & 1200 \\
1800 & 61.4 & 1.35 & 1333.33 \\
4800 & 58.5 & 4.25 & 1129.41 \\
7500 & 56.75 & 6 & 1250 \\
10200 & 55 & 7.75 & 1316.265 \\
12600 & 53.7 & 9.05 & 1392.265 \\
15000 & 52.4 & 10.35 & 1449.275 \\
18000 & 50.85 & 11.9 & 1512.605 \\
21000 & 49.2 & 13.55 & 1549.81 \\
\hline
\end{tabular}


Fig. 10 a Graph of $\left(x_{0}-x\right)$ versus time/ $\left(\mathrm{x}_{0}-\mathrm{x}\right)$; $\mathbf{b}$ graph of $X$ versus $t$; $c$ graph of $X$ versus $\mathrm{N}$; d graph of $\mathrm{K}$ versus $\mathrm{P}_{\mathrm{avg}}$; e graph of temperature versus $x^{*}, y^{*}$

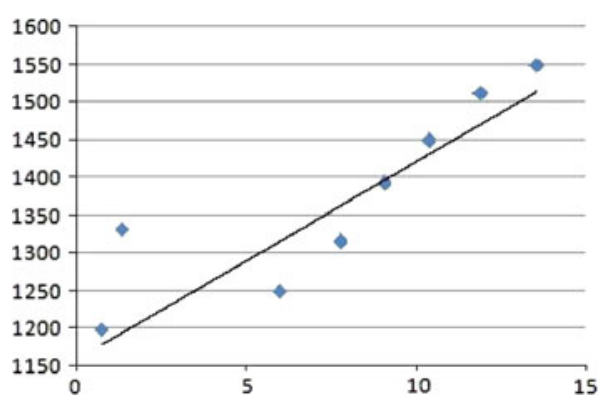

(a)

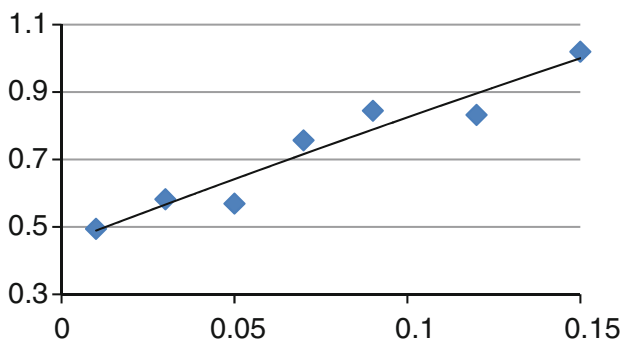

(c)

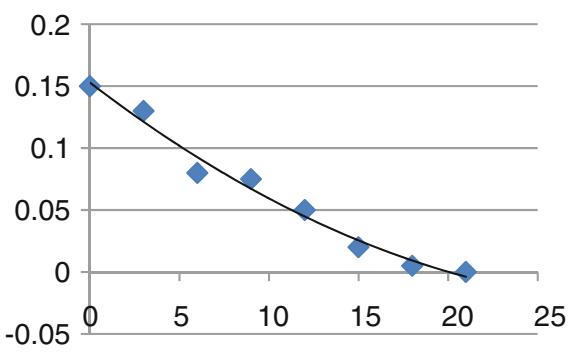

(b)

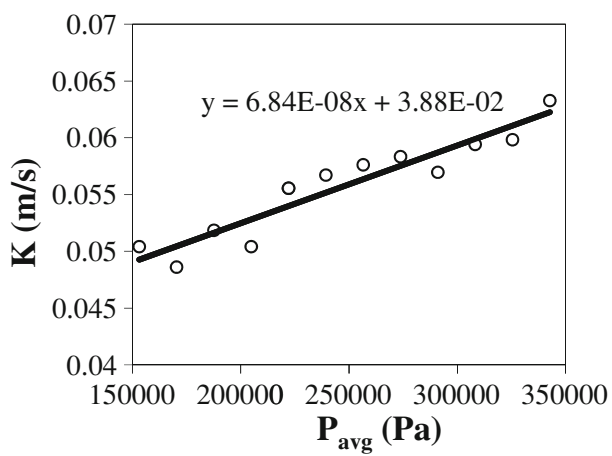

(d)

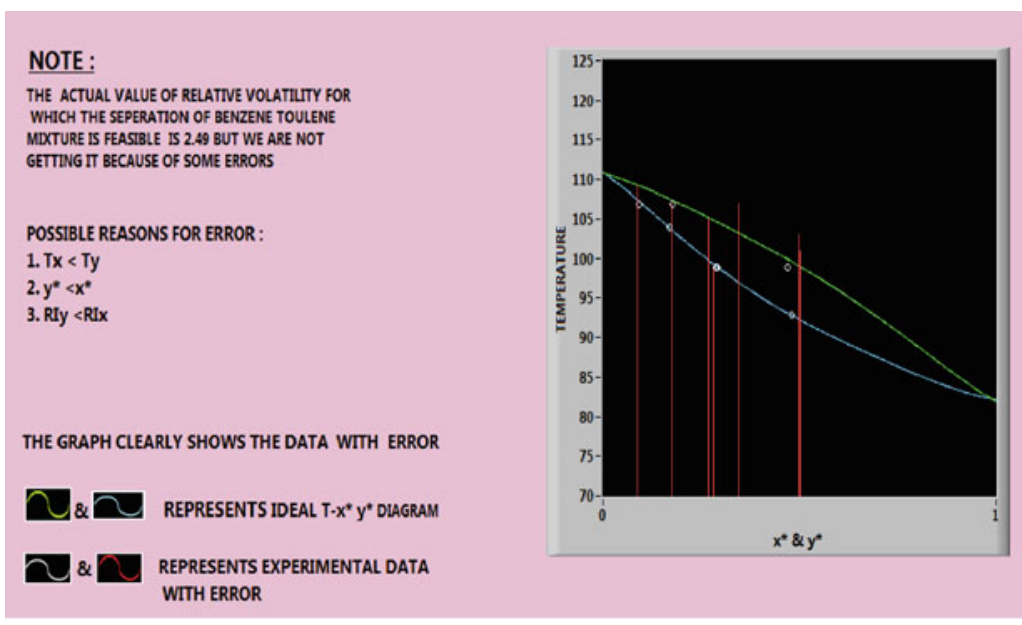

(e)

Table 2 Experimental data for forced draft tray dryer module

\begin{tabular}{lll}
\hline $\begin{array}{l}\text { Time } \\
(\mathrm{t}(\mathrm{s}))\end{array}$ & $\begin{array}{l}\text { Wt. of solid(solid } \\
+ \text { water })(\mathrm{W}(\mathrm{g}))\end{array}$ & $\begin{array}{l}\text { Moisture content } \\
\text { present in solid } \mathrm{X} \\
\text { (g water/g of dry soild) }\end{array}$ \\
\hline 0 & 115 & 0.15 \\
3 & 112 & 0.12 \\
6 & 109 & 0.09 \\
9 & 107 & 0.07 \\
12 & 105 & 0.05 \\
15 & 103 & 0.03 \\
18 & 101 & 0.01 \\
21 & 100 & 0 \\
\hline
\end{tabular}

for the flow through porous media module has been presented in Table 4.

The straight line signifies the standard data trend and the dotted line signifies the experimental/simulated data in Fig. 10d. With this experimental/simulated data further calculations have been carried on using standard formulas and procedures.

(iv) Experimental/simulator calculations for the binary vapor liquid equilibrium module.

The dots and the vertical lines in Fig. 10e signify the experimental data whereas the blue and green curves represent ideal data. 
Table 3 Experimental data forced draft tray dryer module

\begin{tabular}{lllll}
\hline Time (t(s)) & $\begin{array}{l}\text { Wt. of solid } \\
(\text { solid + water }) \\
(\mathrm{W}(\mathrm{g}))\end{array}$ & $\begin{array}{l}\text { Moisture content } \\
\text { present in solid } \mathrm{X} \\
(\mathrm{g} \text { water/g of dry soild })\end{array}$ & $\begin{array}{l}\text { Slope }= \\
-\mathrm{dx} / \mathrm{dt}\end{array}$ & $\begin{array}{l}\mathrm{N} \text { (area const) } \\
\mathrm{g} / \mathrm{s}\end{array}$ \\
\hline 0 & 115 & 0.15 & 0.0102 & 1.02 \\
3 & 112 & 0.12 & 0.009324 & 0.9324 \\
6 & 109 & 0.09 & 0.008448 & 0.8448 \\
9 & 107 & 0.07 & 0.007572 & 0.7572 \\
12 & 105 & 0.05 & 0.006696 & 0.6696 \\
15 & 103 & 0.03 & 0.00582 & 0.582 \\
18 & 101 & 0.01 & 0.004944 & 0.4944 \\
\hline
\end{tabular}

Table 4 Experimental data for flow through porous media module
Table 5 Parameter range for all virtual mass transfer lab modules

\begin{tabular}{llll}
\hline Avg. pressure & Flow rate $\left(\mathrm{m}^{3} / \mathrm{s}\right)(\mathrm{Q})$ & $\mathrm{Q} /(\mathrm{A} * \mathrm{P})$ & $\begin{array}{l}\text { Permeabilty factor } \\
(\mathrm{K})=\mathrm{Q} /(\mathrm{A} * \mathrm{P}) * 101325\end{array}$ \\
\hline 153036.093 & $5.83333 \mathrm{E}-05$ & $4.97588 \mathrm{E}-07$ & 0.050418062 \\
170272.993 & 0.000075 & $4.79817 \mathrm{E}-07$ & 0.048617416 \\
187509.893 & 0.0001 & $5.11804 \mathrm{E}-07$ & 0.051858578 \\
204746.793 & 0.000116667 & $4.97588 \mathrm{E}-07$ & 0.050418062 \\
221983.693 & 0.00015 & $5.48362 \mathrm{E}-07$ & 0.055562762 \\
239220.593 & 0.000175 & $5.59786 \mathrm{E}-07$ & 0.056720319 \\
256457.493 & 0.0002 & $5.68672 \mathrm{E}-07$ & 0.057620642 \\
273694.393 & 0.000225 & $5.7578 \mathrm{E}-07$ & 0.0583409 \\
290931.293 & 0.000241667 & $5.62209 \mathrm{E}-07$ & 0.056965862 \\
308168.193 & 0.000275 & $5.86443 \mathrm{E}-07$ & 0.059421287 \\
325405.093 & 0.0003 & $5.90544 \mathrm{E}-07$ & 0.05983682 \\
342641.993 & 0.000341667 & $6.24523 \mathrm{E}-07$ & 0.063279812 \\
\hline
\end{tabular}

\begin{tabular}{|c|c|c|}
\hline Experiment name & Variables & Range \\
\hline Column Tray Efficiency & $\begin{array}{l}\text { Reflux } \\
\text { Feed composition }\left(\mathrm{x}_{\mathrm{F}}\right) \\
\text { Provided }\left(\mathrm{x}_{\mathrm{B}}>\mathrm{x}_{\mathrm{F}}>\mathrm{x}_{\mathrm{D}}\right) \text { where } \mathrm{B} \text { and } \mathrm{D} \\
\quad \text { designates bottom and distillate product. }\end{array}$ & $\begin{array}{l}1-8 \\
0.3-0.7\end{array}$ \\
\hline $\begin{array}{l}\text { Mass transfer with or without } \\
\text { chemical reaction }\end{array}$ & $\begin{array}{l}\text { Initial length of the cylinder }(\mathrm{cm}) \\
\text { Initial diameter of the cylinder }(\mathrm{cm}) \\
\text { Time for titration }(\mathrm{s})\end{array}$ & $\begin{array}{l}1-10 \\
1-10 \\
600-3600\end{array}$ \\
\hline Binary vapor liquid equilibrium & $\begin{array}{l}\text { Volume fraction of the sample } \\
\text { Temperature }\left({ }^{\circ} \mathrm{C}\right)\end{array}$ & $\begin{array}{l}0.005-0.999 \\
\text { (For calibration) } \\
0.1-1 \\
\text { (For experiment) } \\
\text { Below } 250\end{array}$ \\
\hline Vapor in air diffusion & $\begin{array}{l}\text { Temperature }(\mathrm{K}) \\
\text { Time }(\mathrm{s})\end{array}$ & $\begin{array}{l}298-348 \\
30-420\end{array}$ \\
\hline Forced draft tray dryer & $\begin{array}{l}\text { Moisture content }(\mathrm{ml}) \\
\text { Time (min) }\end{array}$ & $\begin{array}{l}1-20 \\
0-500 \\
S\end{array}$ \\
\hline Water cooling tower & $\begin{array}{l}\text { Liquid flow rate }(\mathrm{L}) \\
\text { Gas flow rate }(\mathrm{G})\end{array}$ & $\begin{array}{l}\text { L/G should lie in } \\
\text { between } 1 \text { and } 2\end{array}$ \\
\hline Rotary dryer & Pressure (cm of water) & $4-10$ \\
\hline Flow through porous media & $\begin{array}{l}\text { Pressure (psi) } \\
\text { Film thickness (microns) }\end{array}$ & $\begin{array}{l}4.5-149.5 \\
1.5-24.5\end{array}$ \\
\hline
\end{tabular}



obtained from users for all modules from various workshops conducted at AEC, Assam and JNTU Kakinada
Table 6 Summary of the inputs

\begin{tabular}{lllll}
\hline Name of the experiment & No. of users & & Typical comments \\
\cline { 2 - 3 } & Online & Offline & \\
\hline Column tray efficiency & 25 & 10 & User friendly \\
Mass transfer with or without & Successful: 24 & & \\
chemical reaction & 32 & 8 & Creative and helpful \\
Binary vapor liquid equilibrium & Successful: 25 & & Easy to operate \\
Vapor in air diffusion & 30 & 8 & Interactive and useful \\
Forced draft tray dryer & Successful: 30 & & \\
Water cooling tower & 40 & 9 & Professional and time savvy \\
Rotary dryer & Successful: 32 & & \\
Flow through porous media & 45 & 12 & Knowledge gaining \\
& Successful: 50 & & Gave a real lab feeling \\
& 35 & 10 & Excellent \\
\hline
\end{tabular}

\subsection{Proximity and scale of operation}

Parametric range for all virtual mass transfer lab modules has been presented in Table 5 .

\subsection{Salient Features of our virtual mass transfer laboratory}

(a) In the vapor in air diffusion module after repeated experimentation we evaluated that the experiment should run for $6 \mathrm{~h}$ and then we should start taking data in time intervals in order to get a correct data set relevant with the theory. But typically students finish it in a maximum of $3 \mathrm{~h}$. The same goes for Column tray efficiency module

(b) For binary vapor liquid equilibrium experiment if done in actual lab, only one composition study can be done in $3 \mathrm{~h}$. So the students can never learn the full spectrum of the VLE. But the simulated module covers these limitations.

(c) Few modules have a case study section. Each case study is laborious and may take few days if done manually. Modules made it easy to handle and learn.

(d) Membrane technology research has been facilitated by e-learning. A single set of experiment will itself take 3-4 days to get valid data and the same can be learnt. But with modules developed it can be done in an hour or two.

\subsection{Field trials/workshops}

Field trails enabled:
- Inclusion of self-explanatory and detailed documentation of the theoretical concepts being conveyed.

- Aspects of randomness and non-ideality were built into the simulator to give a feel of real labs.

- An evaluation mechanism was built into the simulator to evaluate an attempt, in automated fashion.

- Pre and post experimental quizzes were developed and included.

- Inclusion of missing information such as animations, important correlations, units etc.

- Realizing the needs of the learning community, the module could be made more user friendly learning tool.

Till date two grand workshops have been organized at two recognized colleges. These workshops were attended by not only the students and faculties of the respective colleges but also the same from the neighboring colleges and universities. The first workshop was carried out at Assam Engineering College (AEC), Assam, Guwahati and the second was carried out at Jawaharlal Nehru Technological University Kakinada (JNTUK), Andhra Pradesh [9].

Field trials carried during the workshop proved to be lively and gave us a lot of insight to improve our modules. At the end of the workshop students and faculties came up with a view that:

- Virtual lab modules were modeled very close to reallife experiments and when used as a learning tool by students it allowed them to learn the material more efficiently and competently.

- For engineering colleges which do not have access to good lab-facilities such workshops proved to be a good platform for dissemination of knowledge. 
- They enriched their interests in creative programming for better understanding and analysis of various mass transfer phenomena.

- They were very enthused and they inquired about possibilities in other laboratories such as reaction engineering, fluid mechanics, heat transfer, process control etc.

- Few faculty members from other colleges wanted to organize such workshops in their colleges for the benefit of their students.

- Few administrators suggested the need to have long term collaboration between various organizations to facilitate integrated virtual lab development in real experimentation, model development, coding, field trials etc.

Table 6 provides a summary of the inputs obtained from users for all modules from various workshops conducted at AEC, Assam and JNTU Kakinada.

\section{Conclusions}

The objective of the virtual laboratory is to introduce students to experimentation, problem solving, data gathering, and scientific interpretation. It aims to develop and design e-learning modules that enhance the creative competence of the student by targeting non-traditional thought process. In other words, students can be gradually encouraged to develop experiments to enable troubleshooting capabilities in the learning exercises. To date, to the best of our knowledge, there have not been e-learning modules for mass transfer operations, which are very important process operations in chemical, petroleum and biochemical industries.

With the launch of such virtual labs, students can have easy access to an encyclopedia of science and engineering knowledge presented in a way that is engaging, immersive, and enjoyable. Thus the project was started to help the entire student community of India to get best education possible free of cost without the barriers of distance leveraging the ever growing reliable internet connection availability. With the development of new computer technologies, and the World Wide Web, it is now possible to build virtual engineering and science laboratories that can be accessed from all around the world. This design methodology can be extended to other chemical engineering subjects. Students can be engaged at several levels ranging from experimental investigations, code development, and validation apart from field trails. Thereby, creative component can be largely enhanced in the student community. Thereby, by the student, for the student and to the student emphasis of the virtual laboratory concept, would reap rich knowledge transfer dividends in the Indian academic community.

\section{Future Work}

The simulation based mass transfer virtual laboratories can be extended further to newer horizons. Some of these are summarized as follows:

- All software used in developing (and deploying) the simulator should be free and open source.

- Mirror portals to enhance the usability of modules. Presently, only one user can access the virtual laboratory at one time. An alternative for the same is to present executable files at the server database.

- The modules can be made more versatile, generic and user-friendly to cover wide range of chemical and process systems.

- Few more chemical engineering experiments such as steam distillation, evaporative crystallization can be added to the virtual mass transfer laboratory framework.

- Complex process operations such as crude distillation, multi-component absorption can be also targeted, which can enhance the creative component even further to represent more realistic environments.

- Adaptive bandwidth usage to ensure optimum quality of service even in rural areas.

- Online slot booking options to conduct the e-modules can be also targeted for faster dissemination of knowledge transfer protocols across the country.

\section{References}

1. http://www.ni.com/labview/

2. http://www.kcengineers.com/

3. http://iitg.vlab.co.in/?sub=58\&brch=160\& $\operatorname{sim}=752 \& \mathrm{cnt}=1299$

4. http://iitg.vlab.co.in/index.php?sub=58

5. Rao MG, Sittig M (2003) Outlines of chemical technology, 3rd edn. East west press, New Delhi

6. Treybal R (1981) Mass transfer operations, 3rd edn. Mc Graw Hill, Singapore

7. Bulasara VK, Thakuria H, Uppaluri R, Purkait MK (2011) Effect of process parameters on electroless plating and nickelceramic composite membrane characteristics. Desalination 268(1-3):195-203

8. McCabe WL, Smith JC, Harriot P (1993) Unit operations of chemical engineering, 5th edn. Mc Graw Hill, Singapore

9. http://www.thehansindia.info/News/Article.asp?category=5\&sub Category $=2 \&$ Content $I d=48127$ 